\title{
IL-6 and TNF- $\alpha$ serum levels are associated with early death in community-acquired pneumonia patients
}

\author{
M.R. Bacci ${ }^{1}$, R.C.P. Leme ${ }^{1}$, N.P.C. Zing ${ }^{1}$, N. Murad ${ }^{2}$, F. Adami ${ }^{1}$, P.F. Hinnig ${ }^{1}$, D. Feder ${ }^{3}$, \\ A.C.P. Chagas $^{2}$ and F.L.A. Fonseca \\ ${ }^{1}$ Departamento de Cliníca Médica, Faculdade de Medicina do ABC, Santo André, SP, Brasil \\ ${ }^{2}$ Departamento de Cardiologia, Faculdade de Medicina do ABC, Santo André, SP, Brasil \\ ${ }^{3}$ Departamento de Farmacologia, Faculdade de Medicina do ABC, Santo André, SP, Brasil
}

\begin{abstract}
Community-acquired pneumonia (CAP) is amongst the leading causes of death worldwide. As inflammatory markers, cytokines can predict outcomes, if interpreted together with clinical data and scoring systems such as CURB-65, CRB, and Acute Physiology and Chronic Health Evaluation II (APACHE II). The aim of this study was to determine the impact of inflammatory biomarkers on the early mortality of hospitalized CAP patients. Twenty-seven CAP patients needing hospitalization were enrolled for the study and samples of interleukin-1 (IL-1) and interleukin-6 (IL-6), tumor necrosis factor alpha (TNF- $\alpha$ ), C-reactive protein (CRP), and homocystein were collected at the time of admission (day 1) as well as on the seventh day of the treatment. There was a significant reduction in the levels of IL- 6 between the first and the second collections. Median IL- 6 values decreased from $24 \mathrm{pg} / \mathrm{mL}$ (day 1) to $8 \mathrm{pg} / \mathrm{mL}$ (day 7$)(P=0.016)$. The median levels of TNF- $\alpha$ were higher in patients: i) with acute kidney injury (AKI) $(P=0.045)$, ii) requiring mechanical ventilation $(P=0.040)$, iii) with short hospital stays $(P=0.009)$, iv) admitted to the intensive care unit $(I C U)(P=0.040)$, v) who died early $(P=0.003)$, and vi) with worse CRB scores $(P=0.013)$. In summary, IL-6 and TNF- $\alpha$ levels were associated with early mortality of CAP patients. Longer admission levels demonstrated greater likelihood of early death and overall mortality, necessity of mechanical ventilation, and AKI.
\end{abstract}

Key words: Community acquired pneumonia; Interleukin-6; Tumor necrosis factor $\alpha$; Sepsis

\section{Introduction}

Community-acquired pneumonia (CAP) is one of the leading causes of death worldwide and is responsible for large health expenses (1). The inpatient admission rate for CAP has decreased despite the increasing in-hospital mortality rate over the last decade. This dichotomous trend could possibly be explained by the aging of the population and the increase in hospitalization for more severe cases (2). The annual incidence of CAP ranges from 5 to 11 cases per 1000 people in the USA, and it is higher in the elderly (3). In Brazil, children younger than 5 years and adults older than 80 years are the main hospitalized groups (2).

CAP is present during every season, but it is most prevalent in the fall and winter. Streptococcus pneumonia is the main pathogen, followed by Haemophilus influenza. In severe cases, Legionella sp. and Gram-negative bacillus are considered the main pathogens causing CAP (2).

Despite the increase in the incidence and mortality, mostly in the elderly, significant efforts have been made to determine better markers of outcomes during hospitalization. As inflammatory markers, cytokines can predict outcomes if they are interpreted together with clinical data and scoring systems, such as CURB-65, Acute Physiology and Chronic Health Evaluation II (APACHE II) and pneumonia severity index (PSI) (4). However, the correlation between increased cytokine levels due to infections and clinical outcome remains poorly understood. Interleukin-6 (IL-6) is secreted by the white blood cells, such as Tlymphocytes, macrophages, and endothelial cells. Any inflammatory stimulus can increase the IL-6 concentrations and thus can serve as a trigger for other cytokines, such as interleukin-1 (IL-1) and tumor necrosis factor $\alpha$ $(\mathrm{TNF}-\alpha)(5)$.

C-reactive protein ultrasensitive (CRPus) is an acutephase reactive protein, released by the liver into the circulation due to the direct influence of IL-6 after an inflammatory stimulus, such as sepsis (6). Prognosis and survival of CAP

Correspondence: M.R. Bacci: <mrbacci@yahoo.com>.

Received September 21, 2014. Accepted December 11, 2014. First published online February 26, 2015. 
patients have been correlated with CRPus levels less than $100 \mathrm{mg} / \mathrm{L}$ at the time of admission (6).

The primary aim of this study was to determine the impact of inflammatory biomarkers levels on early mortality in a small cohort of hospitalized CAP patients. The secondary objective was to determine the association of cytokines kinetics with clinical data and CAP mortality scores.

\section{Material and Methods}

\section{Study design and population}

A prospective study was conducted by the General Practice Department, Faculdade de Medicina do ABC, from March to August, 2013. This study was approved by their Ethical Committee (approval number: 295.416/2013).

According to the British Thoracic Society definition, CAP is defined as the conditions of acute cough with one of the following signs and symptoms: i) fever lasting for 4 days, ii) dyspnea, iii) tachypnea or new focal chest signs, and iv) a diagnosis confirmed by chest radiography (7).

Patients with a diagnosis of CAP and a maximum onset of $24 \mathrm{~h}$ with treatment were included in this study after obtaining written informed consent. The exclusion criteria were any previous inpatient admission within 30 days of the onset of CAP, end-stage renal disease, human immunodeficiency virus (HIV) or acquired Immune deficiency syndrome (AIDS), neutropenia (defined as less than 1000 neutrophils $/ \mu \mathrm{L}$ ), any immunosuppressive treatment undergone for longer than 3 months, subjected to chemotherapy in the 30 days prior to the onset of CAP, or the coexistence of an infection other than CAP at the time of enrollment.

\section{Data collection and laboratory analysis}

Twenty-milliliter blood samples were collected on the first and seventh day of the treatment. In order to study the relationship between CAP and inflammation, we analyzed serum levels of IL-1, IL-6, TNF- $\alpha$, homocysteine, and CRPus by competitive immunoassay, and chemiluminescence levels were detected with the Immulite 1000 luminometer (Siemens ${ }^{\mathbb{R}}$, Germany). Duplicate analyses were performed at the Clinical Analysis Laboratory, Faculdade de Medicina do ABC.

Data were collected from patient files. Cytokine levels were compared with the demographic and previous clinical condition variables (age, ethnicity and smoking, hypertension, and diabetes status) and with inpatient outcome variables [acute kidney injury (AKI), ICU admission, early death defined as within 7 days of admission, death, length of hospital stay, CURB-65 score, CRB score, chest x-ray involvement, and tracheal intubation necessity]. ICU admission criteria consisted of patients with severe sepsis requiring invasive mechanical ventilation.

\section{Outcome measurements}

The main outcome evaluated consisted of early mortality during hospitalization, which was defined as death occurring within 7 days of admission. Late mortality was defined as death occurring within 30 days of discharge.

Two CAP stratification risk scores, CURB-65 and CRB, were used to predict the inpatient mortality. An APACHE II gravity score was also calculated from the deaths. The ICU admission criteria consisted of the presence of sepsis, hemodynamic collapse, or respiratory failure. AKI was defined as an increase in serum creatinine by $0.3 \mathrm{mg} / \mathrm{dL}$ or by urinary output less than $0.5 \mathrm{~mL} \cdot \mathrm{kg} \cdot \mathrm{h}$ for at least $6 \mathrm{~h}$, according to the Kidney Disease: Improving Global Outcomes (KDIGO) criteria (8). The length of hospital stay (LOS) was defined as the number of days from hospital admission to discharge.

\section{Statistical analysis}

All statistical analyses were performed using the Stata Statistical Package software, version 12.1 (StataCorp., USA). Non-parametric tests were used because of the nonnormal distribution of the data. Confidence interval of $95 \%$ was used in this study.

Serum levels of TNF- $\alpha$, CRPus, IL- 1 , IL- 6 , and homocysteine were compared with the time of collection of the blood samples using the Wilcoxon's signed-rank test. In addition, we used the Wilcoxon's rank-sum test for qualitative variables, the Kruskal-Wallis test for variables with three or more categories, and the Kendall correlation coefficient for continuous variables. Samples with serum levels less than the test detection limit had their means calculated between zero and the corresponding biomarker detection limit.

Variables are reported as medians and interquartile ranges. In Table 1, categorical variables are reported as percent and continuous variables as mean $\pm S D$.

\section{Results}

There was a significant reduction in the levels of IL-6 between the first and the second collections. Median IL-6 values decreased from $24 \mathrm{pg} / \mathrm{mL}$ on day 1 to $8 \mathrm{pg} / \mathrm{mL}$ on day $7(P=0.016)$ (Table 1$)$.

As shown in Table 2, TNF- $\alpha$ levels were associated with gender $(P=0.029)$ and IL-1 levels were correlated with age and ethnicity $(P=0.041)$. The demographic data of the patients suggest that there was no significant association between the inflammation biomarkers and smoking or hypertension (Table 2).

Median levels of TNF- $\alpha$ were higher in patients i) with AKI $(P=0.045)$, ii) requiring mechanical ventilation $(P=0.040)$, iii) with short hospital stays $(P=0.009)$, iv) admitted to the ICU $(P=0.040), v)$ who died early $(P=0.003)$, and vi) with worse CRB scores $(P=0.013)$. Median IL-1 levels were higher in patients with acute respiratory distress syndrome (ARDS; $P=0.010)$, who died early $(P=0.028)$, and those with worse $C R B$ scores $(P=0.002)$.

Similarly, IL-6 levels were higher in patients i) with AKI $(P=0.022)$, ii) requiring tracheal intubation $(P=0.017)$, iii) 
Table 1. TNF- $\alpha$, CRPus, IL-1, IL-6, and homocystein levels in serum at admission (day 1) and day 7 .

\begin{tabular}{lccccc}
\hline & Day 1 & & Day 7 & \multirow{2}{*}{ P $^{*}$} \\
\cline { 2 - 2 } & $\begin{array}{c}\text { Median } \\
(\text { P25-P75 })\end{array}$ & & $\begin{array}{c}\text { Median } \\
(\text { P25-P75) }\end{array}$ & \\
\hline TNF- $\alpha(\mathrm{pg} / \mathrm{mL})$ & $7.6(5.8-14.4)$ & $8.5(6.8-16.9)$ & 0.470 \\
CRPus $(\mathrm{mg} / \mathrm{L})$ & $67.1(40.6-100)$ & & $49.5(13.2-100)$ & 0.267 \\
IL-1 $(\mathrm{pg} / \mathrm{mL})$ & $2.5(2.5-2.5)$ & & $2.5(2.5-2.5)$ & 0.317 \\
IL-6 $(\mathrm{pg} / \mathrm{mL})$ & $24.0(7.4-55.6)$ & & $8.0(3.7-44.9)$ & 0.016 \\
Homocystein $(\mu \mathrm{mol} / \mathrm{L})$ & $12.2(1.0-16.3)$ & & $13.9(2.8-20)$ & 0.278 \\
\hline
\end{tabular}

Data are reported as median (interquartile range; $n=13-15$ ). TNF- $\alpha$ : tumor necrosis factor alpha; CRPus: C-reactive protein ultrasensitive; IL: interleukin. ${ }^{*} \mathrm{P}$, day 7 compared to day 1 (Wilcoxon signed-rank test).

with ARDS $(P=0.008)$, iv) admitted to the ICU $(P=$ $0.017)$, v) who died $(P=0.040)$, and vi) who died early $(P=0.003$; Table 3).
Creatinine levels in the regression model showed statistical associations with TNF- $\alpha(P=0.02), I L-1(P=0.03)$, and IL-6 $(P=0.02)$. However, there was no correlation of hemoglobin with TNF- $\alpha(P=0.01$; Table 4).

The patients who died had a mean age of $65.5 \pm 12.3$ years and a mean APACHE II score of $26.6 \pm 7.22$ years, representing an odds of death of $40 \%$ among non-surgery patients. The average hospitalization time was $5.4 \pm 5$ days, and $60 \%$ of the patients were men.

\section{Discussion}

Higher serum levels of inflammatory cytokines, such as IL- 6 and TNF- $\alpha$, have been correlated with worse outcomes. A persistently high value can suggest an unfavorable outcome. Inflammatory cytokine levels in serum, measured in our cohort during the peak of CAP season in Brazil, showed similar IL- 6 and TNF- $\alpha$ levels between the elderly and the younger populations, the Caucasian and the non-Caucasian populations, and the male and the female patients.

Table 2. TNF- $\alpha$, CRPus, IL-1, IL-6, and homocystein levels in serum according to the demographic and clinical patient data.

\begin{tabular}{|c|c|c|c|c|c|c|c|c|c|c|}
\hline & \multicolumn{2}{|c|}{ TNF- $\alpha(p g / m L)$} & \multicolumn{2}{|c|}{ CRPus (mg/L) } & \multicolumn{2}{|c|}{$\mathrm{IL}-1$ (pg/mL) } & \multicolumn{2}{|c|}{ IL-6 (pg/mL) } & \multicolumn{2}{|c|}{$\begin{array}{l}\text { Homocystein } \\
(\mu \mathrm{mol} / \mathrm{L})\end{array}$} \\
\hline & $\begin{array}{l}\text { Median } \\
\text { (P25-P75) }\end{array}$ & $P$ & $\begin{array}{c}\text { Median } \\
\text { (P25-P75) }\end{array}$ & $\mathrm{P}$ & $\begin{array}{l}\text { Median } \\
\text { (P25-P75) }\end{array}$ & $\mathrm{P}$ & $\begin{array}{c}\text { Median } \\
\text { (P25-P75) }\end{array}$ & $P$ & $\begin{array}{c}\text { Median } \\
\text { (P25-P75) }\end{array}$ & $P$ \\
\hline Age (years) & & 0.427 & & 0.186 & & 0.041 & & 0.123 & & 0.145 \\
\hline$<60(n=13)$ & $\begin{array}{c}11.5 \\
(6.4-21.6)\end{array}$ & & $\begin{array}{c}100.0 \\
(67.1-100.0)\end{array}$ & & $\begin{array}{c}2.5 \\
(2.5-2.5)\end{array}$ & & $\begin{array}{c}23.7 \\
(7.4-33.0)\end{array}$ & & $\begin{array}{c}8.9 \\
(1.0-14.1)\end{array}$ & \\
\hline$\geqslant 60(n=13)$ & $\begin{array}{c}13.7 \\
(6.8-21.3)\end{array}$ & & $\begin{array}{c}70.5 \\
(40.6-100.0)\end{array}$ & & $\begin{array}{c}2.5 \\
(2.5-5.6)\end{array}$ & & $\begin{array}{c}33.0 \\
(20.6-320.0)\end{array}$ & & $\begin{array}{c}14.3 \\
(11.1-19.5)\end{array}$ & \\
\hline Ethnicity & & 0.397 & & 0.388 & & 0.041 & & 0.150 & & 0.696 \\
\hline Caucasian $(n=13)$ & $\begin{array}{c}13.7 \\
(6.8-21.6)\end{array}$ & & $\begin{array}{c}79.9 \\
(40.6-100.0)\end{array}$ & & $\begin{array}{c}2.5 \\
(2.5-5.6)\end{array}$ & & $\begin{array}{c}33.0 \\
(20.6-320.0)\end{array}$ & & $\begin{array}{c}12.0 \\
(1.0-16.3)\end{array}$ & \\
\hline Black $(n=13)$ & $\begin{array}{c}9.8 \\
(6.4-18.6)\end{array}$ & & $\begin{array}{c}100.0 \\
(66.5-100.0)\end{array}$ & & $\begin{array}{c}2.5 \\
(2.5-2.5)\end{array}$ & & $\begin{array}{c}23.7 \\
(13.1-33.3)\end{array}$ & & $\begin{array}{c}12.2 \\
(8.9-15.8)\end{array}$ & \\
\hline Gender & & 0.029 & & 0.787 & & 0.233 & & 0.268 & & 0.389 \\
\hline Male $(n=14)$ & $\begin{array}{c}6.8 \\
(5.4-18.6)\end{array}$ & & $\begin{array}{c}100.0 \\
(40.6-100.0)\end{array}$ & & $\begin{array}{c}2.5 \\
(2.5-2.5)\end{array}$ & & $\begin{array}{c}24.3 \\
(13.1-33.3)\end{array}$ & & $\begin{array}{c}9.7 \\
(1.0-17.9)\end{array}$ & \\
\hline Female $(n=12)$ & $\begin{array}{c}15.4 \\
(12.2-39.5)\end{array}$ & & $\begin{array}{c}77.2 \\
(64.0-100.0)\end{array}$ & & $\begin{array}{c}2.5 \\
(2.5-4.1)\end{array}$ & & $\begin{array}{c}41.6 \\
(18.0-660.0)\end{array}$ & & $\begin{array}{c}13.4 \\
(6.5-16.1)\end{array}$ & \\
\hline Smoking & & 0.146 & & 0.126 & & 0.111 & & 0.553 & & 0.219 \\
\hline No $(n=17)$ & $\begin{array}{c}13.7 \\
(8.3-28.5)\end{array}$ & & $\begin{array}{c}70.5 \\
(53.9-100.0)\end{array}$ & & $\begin{array}{c}2.5 \\
(2.5-4.1)\end{array}$ & & $\begin{array}{c}27.9 \\
(18.5-190.0)\end{array}$ & & $\begin{array}{c}12.4 \\
(8.9-16.3)\end{array}$ & \\
\hline Yes $(n=9)$ & $\begin{array}{c}6.8 \\
(5.4-18.6)\end{array}$ & & $\begin{array}{c}100.0 \\
(100.0-100.0)\end{array}$ & & $\begin{array}{c}2.5 \\
(2.5-2.5)\end{array}$ & & $\begin{array}{c}24.3 \\
(13.1-33.3)\end{array}$ & & $\begin{array}{c}4.0 \\
(1.0-14.1)\end{array}$ & \\
\hline Hypertension & & 0.129 & & 0.685 & & 0.668 & & 0.487 & & 0.389 \\
\hline No $(n=12)$ & $\begin{array}{c}17.1 \\
(10.7-34.4)\end{array}$ & & $\begin{array}{c}78.3 \\
(48.3-100.0)\end{array}$ & & $\begin{array}{c}2.5 \\
(2.5-2.5)\end{array}$ & & $\begin{array}{c}41.6 \\
(14.0-603.5)\end{array}$ & & $\begin{array}{c}7.3 \\
(1.0-15.5)\end{array}$ & \\
\hline Yes $(n=14)$ & $\begin{array}{c}7.6 \\
(5.8-16.4)\end{array}$ & & $\begin{array}{c}90.0 \\
(61.4-100.0)\end{array}$ & & $\begin{array}{c}2.5 \\
(2.5-2.5)\end{array}$ & & $\begin{array}{c}24.3 \\
(15.8-33.3)\end{array}$ & & $\begin{array}{c}13.2 \\
(8.9-17.9)\end{array}$ & \\
\hline
\end{tabular}

Data are reported as median (interquartile range). TNF- $\alpha$ : tumor necrosis factor alpha; CRPus: C-reactive protein ultrasensitive; IL: interleukin. $P$ values were obtained with Wilcoxon's rank-sum test and the Kruskal-Wallis test. 


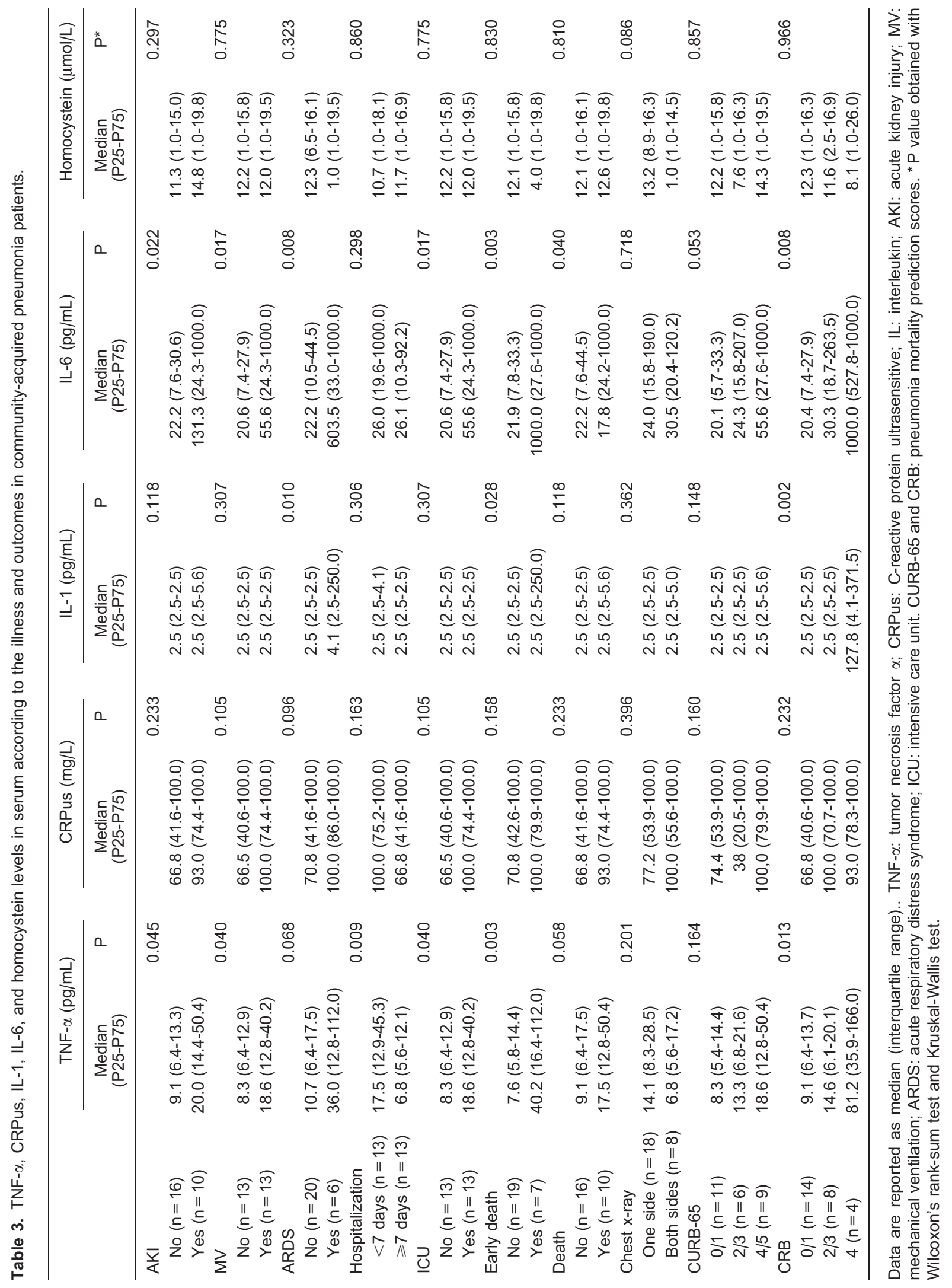


Table 4. Logistic regression model between cytokines and biochemical markers in community-acquired pneumonia patients.

\begin{tabular}{lrrrrr}
\hline & TNF- $\alpha(\mathrm{pg} / \mathrm{mL})$ & CRPus $(\mathrm{mg} / \mathrm{L})$ & $\mathrm{IL}-1(\mathrm{pg} / \mathrm{mL})$ & $\mathrm{IL}-6(\mathrm{pg} / \mathrm{mL})$ & $\begin{array}{c}\text { Homocystein } \\
(\mu \mathrm{mol} / \mathrm{L})\end{array}$ \\
\hline Urea $(\mathrm{mg} / \mathrm{dL})$ & $0.23(0.10)$ & $0.10(0.47)$ & $0.18(0.05)$ & $0.26(0.07)$ & $0.11(0.42)$ \\
Creatinine $(\mathrm{mg} / \mathrm{dL})$ & $0.34(0.02)$ & $0.09(0.53)$ & $0.20(0.03)$ & $0.31(0.02)$ & $0.16(0.24)$ \\
Hemoglobin $(\mathrm{g} / \mathrm{dL})$ & $-0.36(0.01)$ & $0.05(0.71)$ & $-0.08(0.42)$ & $-0.09(0.52)$ & $-0.19(0.18)$ \\
\hline
\end{tabular}

Data are reported as the Kendall correlation coefficient (P-value). TNF- $\alpha$ : tumor necrosis factor alpha; CRPus: C-reactive protein ultrasensitive; IL: interleukin.

Surprisingly, unlike IL- 6 and TNF- $\alpha$, the levels of CRPus and homocysteine, the latter being a marker of oxidative stress, were not predictive of LOS, early death, or mortality.

\section{Pneumonia mortality scores}

Prognostic scores are usually helpful in deciding if a patient can be discharged. The American Thoracic Society recommends the hospitalization of patients with a score higher than $2(9,10)$. CURB-65 is an interesting tool, but it is not a good predictor of mortality (11).

We showed that, despite high scores among hospitalized patients, the CURB-65 score was not correlated with the inflammatory biomarkers used in this series. However, the CRB score demonstrated a closer association with the levels of IL-1, IL-6, and TNF- $\alpha$ in our cohort.

\section{AKI and sepsis}

The occurrence of $\mathrm{AKI}$ in the setting of sepsis increases the odds of an adverse outcome (12). Murugan et al. (12) showed that, despite this correlation, lesser importance was given to non-severe cases of CAP, which underwent worse progression, when AKI was associated. Patients with higher CURB-65 scores have a higher incidence of AKI.

The high mortality rates seen in this cohort must be analyzed with the conditions that developed during the treatment of each patient. The mean APACHE II score was 26.6 , and $38.4 \%$ of the patients had AKI. Approximately, $50 \%$ of the patients were older than 60 years of age, which also contributed to the worse outcomes. ARDS was present in 6 patients, and all of them died.

Martinez et al. (13) showed that worse outcomes in CAP sepsis patients were associated with inadequate management of the initial treatment. When recognized as having sepsis, the CAP patients received an initial treatment based on sepsis guidelines (14), which had a positive impact on their outcomes.

\section{IL-6 and TNF- $\alpha$}

IL-6 levels have shown a good association with the prediction scores, such as APACHE II and CURB-65 (15, 16). We showed that amongst all the analyzed cytokines, higher levels of IL-6 were associated with the development of $\mathrm{AKI}$, the necessity of invasive mechanical ventilation, higher LOS, early death, and mortality. Glyn et al. (16) showed strong correlations between IL- 6 levels and the APACHE II as well as CURB-65 outcome prediction scores. As a pro-inflammatory cytokine, IL-6 also stimulates counter-inflammatory regulation with the production of IL-10. Therefore, the CAP patients undergo immunomodulation to prevent the deleterious effects of the proinflammatory cascade $(17,18)$.

TNF- $\alpha$ levels were also correlated with IL- 6 outcomes. Higher levels of both cytokines at the time of admission predicted worse outcomes. TNF- $\alpha$ levels in pneumonia patients were higher in the lungs than in the plasma (13). Thus, IL-6 reacts strongly to the local pneumococcal aggression, resulting in the systemic release of antigens and cytokines (13).

However, blood sample collection time, due to the initiation of antimicrobial therapy and the progression of CAP, did have effects on the initial values of these cytokines. We standardized the time of blood sample collection to the first $24 \mathrm{~h}$, following admission (day 1) and to day 7, for proper evaluation of the progression of the treatment and the decrease in the levels of the cytokines.

However, this study has some limitations. It was a single center study with a limited sample size and therefore, had a robust statistical approach. The blood samples were collected within fixed intervals and patients with longer hospitalization duration were not accessed after 7 days. Moreover, as an intention to treat analysis, the patients with higher CURB-65 scores at admission were not withdrawn from of the sample.

The bacterial isolation had a poor impact on the outcomes, with the culture-directed therapy having the same outcomes as that of the empirical antimicrobial therapy, based on the most prevalent pathogens (9). The IL-6 levels were also found to be higher in pneumococcal CAP patients when identified by positive culture (13).

In summary, IL-6 and TNF- $\alpha$ levels were associated with early death, compared with standard scores of CURB65 and CRB. Higher admission levels demonstrated greater likelihood of early death and mortality, necessity of invasive mechanical ventilation, and AKI. 


\section{References}

1. Teepe J, Grigoryan L, Verheij TJ. Determinants of community-acquired pneumonia in children and young adults in primary care. Eur Respir J 2010; 35: 1113-1117, doi: 10.1183/ 09031936.00101509.

2. Corrêa R de A, Lundgren FL, Pereira-Silva JL, Frare e Silva $\mathrm{RL}$, Cardoso AP, Lemos AC, et al. Brazilian guidelines for community-acquired pneumonia in immunocompetent adults - 2009. J Bras Pneumol 2009; 35: 574-601, doi: 10.1590/ S1806-37132009000600011.

3. Xiao K, Su LX, Han BC, Yan P, Yuan N, Deng J, et al. Analysis of the severity and prognosis assessment of aged patients with community-acquired pneumonia: a retrospective study. J Thorac Dis 2013; 5: 626-633.

4. Ramirez P, Ferrer M, Marti V, Reyes S, Martinez R, Menendez $\mathrm{R}$, et al. Inflammatory biomarkers and prediction for intensive care unit admission in severe community-acquired pneumonia. Crit Care Med 2011; 39: 2211-2217, doi: 10.1097/CCM. 0b013e3182257445.

5. Heinrich PC, Behrmann I, Haan S, Hermanns HM, MullerNewen G, Schaper F. Principles of interleukin (IL)-6-type cytokine signalling and its regulation. Biochem J 2003; 374: 1-20, doi: 10.1042/BJ20030407.

6. Chalmers JD, Singanayagam A, Hill AT. C-reactive protein is an independent predictor of severity in community-acquired pneumonia. Am J Med 2008; 121: 219-225, doi: 10.1016/ j.amjmed.2007.10.033.

7. Levy ML, Le Jeune I, Woodhead MA, Macfarlaned JT, Lim WS. Primary care summary of the British Thoracic Society Guidelines for the management of community acquired pneumonia in adults: 2009 update. Endorsed by the Royal College of General Practitioners and the Primary Care Respiratory Society UK. Prim Care Respir J 2010; 19: 21 27, doi: 10.4104/pcrj.2010.00014.

8. Kellum JA, Lameire N. Diagnosis, evaluation, and management of acute kidney injury: a KDIGO summary (Part 1). Crit Care 2013; 17: 204, doi: 10.1186/cc11454.

9. Mandell LA, Wunderink RG, Anzueto A, Bartlett JG, Campbell GD, Dean NC, et al. Infectious Diseases Society of America/American Thoracic Society consensus guidelines on the management of community-acquired pneumonia in adults. Clin Infect Dis 2007; 44 (Suppl 2): S27-S72, doi: $10.1086 / 511159$
10. Capelastegui A, Espana PP, Quintana JM, Areitio I, Gorordo I, Egurrola M, et al. Validation of a predictive rule for the management of community-acquired pneumonia. Eur Respir J 2006; 27: 151-157, doi: 10.1183/09031936.06.00062505.

11. Yandiola PP, Capelastegui A, Quintana J, Diez R, Gorordo I, Bilbao A, et al. Prospective comparison of severity scores for predicting clinically relevant outcomes for patients hospitalized with community-acquired pneumonia. Chest 2009; 135: 1572-1579, doi: 10.1378/chest.08-2179.

12. Murugan R, Karajala-Subramanyam V, Lee $M$, Yende $S$, Kong $\mathrm{L}$, Carter $\mathrm{M}$, et al. Acute kidney injury in non-severe pneumonia is associated with an increased immune response and lower survival. Kidney Int 2010; 77: 527-535, doi: 10.1038/ki.2009.502.

13. Martinez R, Menéndez R, Reyes S, Polverino E, Cilloniz C, Martinez $A$, et al. Factors associated with inflammatory cytokine patterns in community-acquired pneumonia. Eur Respir J 2011; 37: 393-399, doi: 10.1183/09031936.00040710.

14. Dellinger RP, Levy MM, Rhodes A, Annane D, Gerlach H, Opal SM, et al. Surviving Sepsis Campaign: international guidelines for management of severe sepsis and septic shock, 2012. Intensive Care Med 2013; 39: 165-228, doi: 10.1007/s00134-012-2769-8.

15. Antunes G, Evans SA, Lordan JL, Frew AJ. Systemic cytokine levels in community-acquired pneumonia and their association with disease severity. Eur Respir J 2002; 20: 990-995, doi: 10.1183/09031936.02.00295102.

16. Glynn P, Coakley R, Kilgallen I, Murphy N, O'Neill S. Circulating interleukin 6 and interleukin 10 in community acquired pneumonia. Thorax 1999; 54: 51-55, doi: 10.1136/ thx.54.1.51.

17. Zobel K, Martus P, Pletz MW, Ewig S, Prediger M, Welte T, et al. Interleukin 6, lipopolysaccharide-binding protein and interleukin 10 in the prediction of risk and etiologic patterns in patients with community-acquired pneumonia: results from the German competence network CAPNETZ. BMC Pulm Med 2012; 12: 6, doi: 10.1186/1471-2466-12-6.

18. Ortqvist A, Hedlund J, Wretlind B, Carlstrom A, Kalin M. Diagnostic and prognostic value of interleukin-6 and Creactive protein in community-acquired pneumonia. Scand $J$ Infect Dis 1995; 27: 457-462, doi: 10.3109/00365549509 047046. 